\title{
Foams stabilized with nanoparticles for gas well deliquification
}

\author{
Ewa Knapik $^{1 *}$, Jerzy Stopa ${ }^{1}$, Anna Marzec ${ }^{2}$ \\ ${ }^{1}$ AGH University of Science and Technology in Krakow, Faculty of Drilling, Oil and Gas, 30 Mickiewicza Ave., 30-059 \\ Krakow \\ ${ }^{2}$ AGH University of Science and Technology in Krakow, Faculty of Materials Science and Ceramics, 30 Mickiewicza \\ Ave., 30-059 Krakow \\ *Corresponding author: e-mail: eknapik@agh.edu.pl
}

\begin{abstract}
This study examined the interaction of solid nanoparticles and anionic and non-ionic surfactant at an air-water interface. Aqueous foams stabilized by silica nanoparticles in water with different levels of salinity were studied in detail. The stability of solid/surfactant dispersion was evaluated visually. Nanoparticles content impact and concentration of surfactant on the foamability, deliquification of foams and structure of wet foams were studied. It was found that the foamability of dispersion depends either on the surfactant concentration or on the nanoparticles concentration. The adsorption of hydrophobically modified silica particles and surfactants reduces the air/water interface tension. The results of the examinations showed that the use of nanoparticles allows to increase the efficiency of brine unloading even up to $20 \%$. Surfactant particle and nanosilica present synergistic action, use of $4 \mathrm{wt} \%$ of nanoparticles allows to reduce surfactant consumption up to half. The cost of the preparation of the proposed dispersion is slightly higher, about $5 \%$, compared to the sole surfactant.
\end{abstract}

Keywords: Foam, foamability, solid nanoparticles, surfactant.

\section{INTRODUCTION}

The most frequent cause of limiting gas wells productivity is a considerable formation water supply connected with a decrease in pressure during reservoir exploitation ${ }^{1}$. There are many mechanical methods to prevent water formation, mainly blow out and pumping by rod pumps use ${ }^{2}$, but due to a cost and easy application the chemical methods enjoy greater interest ${ }^{3,4}$. Dosage of surfactants solutions to wellbore is aimed to create stable foam, which thanks to much smaller density than initial brine, may be taken out by the flowing gas. A high temperature of the reservoir, water salinity and presence of hydrocarbon condensate limit an application of this method, which destroy the dsorbed thin layer of surfactant causing drainage/collapse of foam ${ }^{5,6}$. For many years nanoparticles have been used as stabilizers of two-phase systems, both emulsions - Pickering emulsions as well as foams ${ }^{7-10}$. So far examined the nanoparticles impact on foams stability, produced with a use of cationic and non-ionic surfactants, in addition, measurements usually were conducted in stationary conditions ${ }^{\mathbf{1 1}, \mathbf{1 2}}$. The aim of this work is examination of foamability and foam stability produced using industrially available surfactants stabilized hydrophobic nanoparticles. The proposed solution will allow to reduce an individual consumption of chemicals as well as will widen this method application possibility to remove water formation to deeper wells with higher salinity.

\section{EXPERIMENTAL}

\section{Material}

In examinations the Sicol Z, which is a mixture of anionic and non-ionic surfactants available by courtesy of PGNiG SA (Polish Oil \& Gas Company - PGNiG Capital Group) was applied as surfactant. Synthetic brine was prepared by dissolving $\mathrm{NaCl}$ and $\mathrm{CaCl}_{2}$ (analytically pure) in the distilled water. Hydrophobic silica nanoparticles with an average primary particle size of $15 \mathrm{~nm}$ and specific surface area as high as $170 \mathrm{~m}^{2} / \mathrm{g}$ from Dynamic Design Company was used. All chemicals were used as received without further purification.

\section{Experimental methods}

Nanosilica was dispersed in Sicol Z (as received from the manufacturer) by blending with the speed of 1500 rpm for 30 minutes. Dispersion stability was assessed visually, directly after blend and 24 hours later. Density of mixtures was measured by pycnometer, viscosity at $20^{\circ} \mathrm{C}$ with the capillary method. Brine was obtained by dissolving $100 \mathrm{~g}$ of $\mathrm{NaCl}$ and $10 \mathrm{~g}$ of $\mathrm{CaCl}_{2}$ in $1 \mathrm{dm}^{3}$ of the distilled water.

Surface tension measurement was performed using tensiometer TD1 of the Lauda Company.

The stability of the foam for different surfactant and nanosilica concentrations in distilled water as well as in brine was determined by comparing the height of foam directly after energetic one-minute shake out and after 3 hours. Foam density defined as the volume ratio of liquid converted into foam to the volume of the created foams was determined after shaking ${ }^{5}$. Foaming ability was indicated in dynamic conditions according to a modified Bikerman method ${ }^{3}$. In Bikerman's classical method, a certain amount of liquid is poured into a graduated column and gas is bubbled at a constant flow rate in the liquid through some frit. The foam accumulates in the column and when the foam column height reaches a stable value, the gas input is closed and the foam column height is monitored versus time. In the case of gas wells without packer in certain operating conditions, the foam can be taken out in an annular space. The annular flow is used as a modification of Bikerman method. The formed foam was brought out of the column into a separate container. Test apparatus is presented in Figure 1.

\section{RESULTS}

Hydrophobic silica nanoparticles easily disperse in Sicol $\mathrm{Z}$ and create stable dispersions, after 24 hours there is no delamination. The appearances of dispersions 


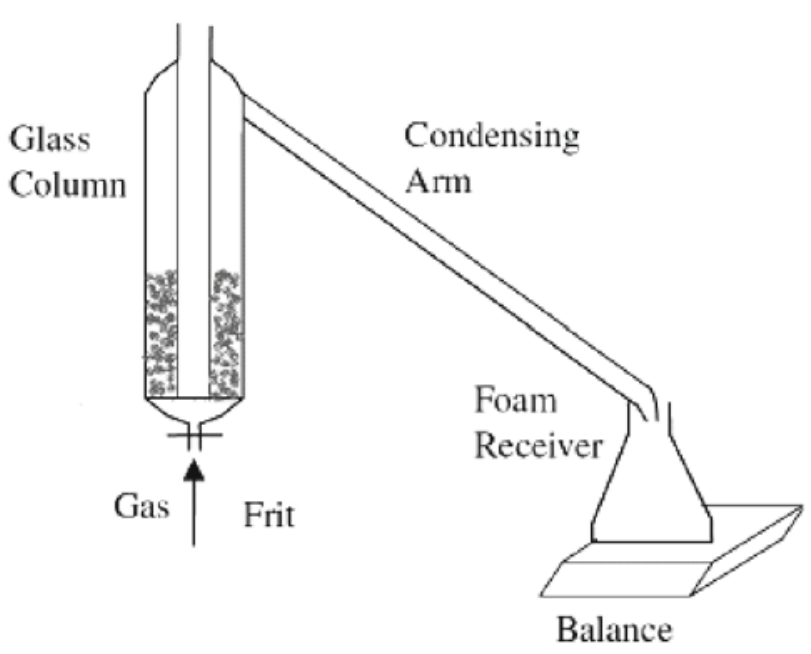

Figure 1. Schematic illustration of the dynamic foaming test apparatus [3, modified]

with different concentrations of nanosilica are shown in Figure 2. The cost of the preparation of the proposed dispersion is low due to an easy availability of nanosilica and its low concentration in dispersion.

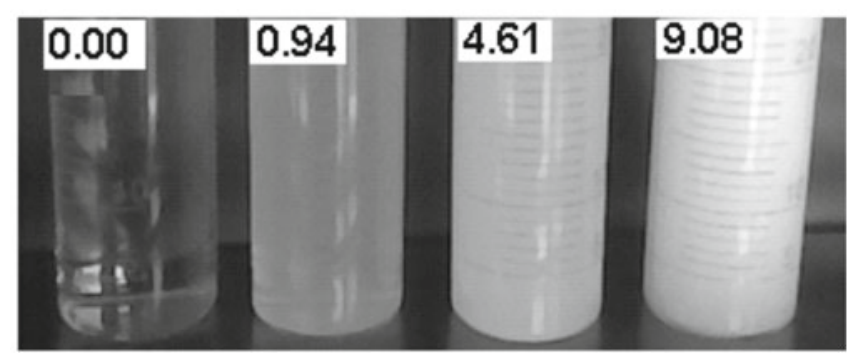

Figure 2. Appearance of the nanosilica dispersion/Sicol $\mathrm{Z}$ after 24 hours. The concentrations of nanosilica (wt\%) are shown in the Figure

The produced dispersions are stable due to strong interaction between the hydrophobic surface of silica and anionic as well as non-ionic surfactants molecules. Due to a complex composition of the used mixtures, a few adsorption mechanisms ${ }^{7,11,13}$ including ion exchange, ion pairing and hydrophobic interactions must be expected. Formation of nanoparticle - non-ionic surfactant aggregates increasing the viscosity of dispersion and repulsive interactions between negatively charged nanosilica surfaces and functional groups of anionic surfactants stabilize the obtained dispersions.

Liquid foaming additives are overcrowding in a constant way using capillary columns about diameter not greater than $9.5 \mathrm{~mm}$. Such a solution causes higher consumption of surfactants in comparing to foaming sticks application. On the other hand, it reduces fluctuation of the bottom pressure and allows for precise dosage of chemical agents. Embossed liquid in order to freely flow must have an appropriate density and viscosity, the addition of solid nanosilica significantly impacts on these parameters, as it was described in Table 1.

From Table 1 it results that a maximum useful concentration of nanoparticles in the dispersion is about $5 \mathrm{wt} \%$, above this concentration the viscosity of mixture considerably grows, what hampers pumping and creates the risk of freezing in surface installation parts in a winter period.
Table 1. Viscosity and density of the nanosilica dispersion/Sicol $\mathrm{Z}$ at $20^{\circ} \mathrm{C}$

\begin{tabular}{|l|l|l|l|l|l|}
\hline $\begin{array}{l}\text { Nanosilica } \\
\text { concentration } \\
{[\% \text { mass] }}\end{array}$ & 0 & 0.94 & 1.87 & 4.61 & 9.08 \\
\hline Density $\left[\mathrm{g} / \mathrm{cm}^{3}\right]$ & 1.0598 & 1.063 & 1.0694 & 1.0849 & 1.1012 \\
\hline $\begin{array}{l}\text { Dynamic } \\
\text { viscosity }[\mathrm{Pa} \cdot \mathrm{s}]\end{array}$ & 0.0108 & 0.0297 & 0.0526 & 0.0886 & 2.4325 \\
\hline
\end{tabular}

Foam formation is a complex process dependent mainly on the surface phenomena ${ }^{\mathbf{1 2}} \mathbf{1 4}$. Adsorption mechanism of solid particles as well as surfactant on the interfacial surface depends on the chemical substance character. In Figure 3 the Sicol $\mathrm{Z}$ impact and its dispersion with nanoparticles on the surface tension was presented.

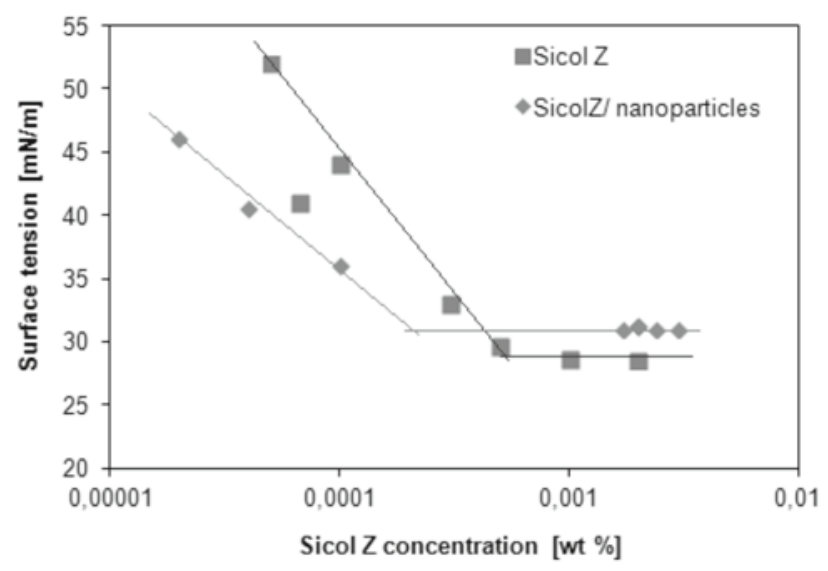

Figure 3. Isotherms of the surface tension for Sicol $\mathrm{Z}$ and Sicol Z/nanosilica mixture $(4.61 \mathrm{wt} \%)$

Along with increase in the Sicol $\mathrm{Z}$ concentration a decrease of surface tension is observed, until it reaches critical micellar concentrations (CMC), above which the tension doesn't change. For low surfactant concentrations the addition of hydrophobic nanosilica causes higher reduction in surface tension. In the presence of solid nanoparticles the interfacial area covers both surfactant particle and nanosilica; therefore dispersion has lower CMC than for pure Sicol Z.

The presence of nanoparticles in solution greatly impacts on the effectiveness brine unloading, what the foamability dynamic test confirms (Fig. 4).

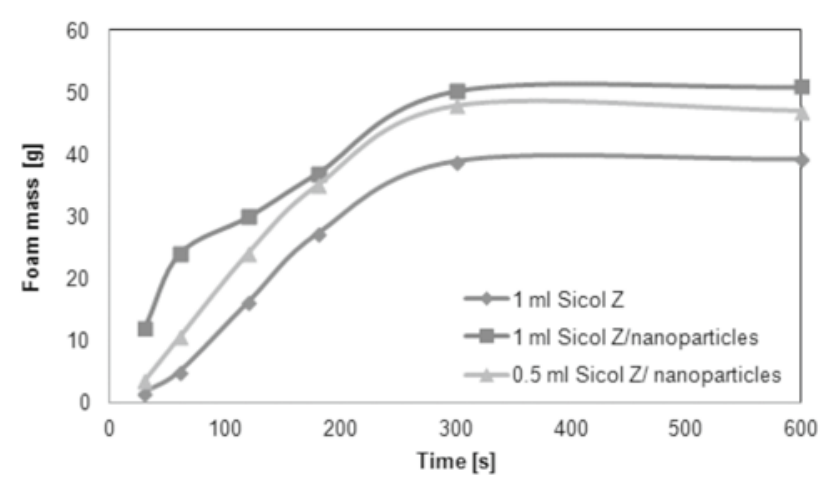

Figure 4. Comparison of the effectiveness brine loading up by Sicol $\mathrm{Z}$ without and in presence of solid nanoparticles $(0.5 \mathrm{wt} \%)$

The applied measurement system (annular flow and narrowing at the outlet of foam) simulate actual difficulties encountered by well operation. The measurement was conducted at room temperature and at a fixed flow rate 
of $1 \mathrm{~m} / \mathrm{s}$. A $100 \mathrm{ml}$ sample of the foaming solution was introduced into the column. Some of the foaming solutions contain Sicol Z at a 0.2 or $1 \mathrm{v} / \mathrm{v} \%$ concentration in brine. Other tested foaming solutions contain the nanosilica dispersion/Sicol $\mathrm{Z}$ at a 0.5 or $1 \mathrm{v} / \mathrm{v} \%$ concentration in brine. The concentration of nanosilica in dispersion is $0.5 \mathrm{wt} \%$. The mass of the liquid unloaded by foam versus time was used to quantify the effectives of the foam.

At low concentrations Sicol Z, below $0.2 \mathrm{v} / \mathrm{v} \%$ (not shown in the figure), don't arise to unload foam, i.e. formation of the foam is observed in the pipe, but in insufficient amount to achieve the overflow pipe. In industrial practice the concentration of about $1 \mathrm{v} / \mathrm{v} \%$ of foaming agent is usually applied; at this concentration Sicol Z unloads $39 \mathrm{~g}$ of the foam. The same amount of surfactant, but with the addition of nanoparticles, increases the amount of unloading the foam up to $50 \mathrm{~g}$. It is a great progress, since in real conditions it may remove even a few tons of water from the well per day, and the less water in this well the greater gas production. Dispersion shows the synergistic effect, nanoparticles application allows to reduce the consumption of surfactant by half, at $0.5 \mathrm{v} / \mathrm{v} \%$ of foaming the foam unloads $48 \mathrm{~g}$ of water.

The effectiveness of unloading brine by nanoparticles dispersion can be simply explained by a thin layer structure on the gas bubble surface (Fig. 5).

Surfactants adsorb on the liquid-air interface, in such a way that hydrophilic functional groups are immersed in a liquid, and hydrophobic part are directed toward the $\operatorname{air}^{14}$. In a process of dewatering the liquid is trapped between two adsorbate monolayers and held by van der Waals forces through hydrophilic groups of the surfactant (Fig. 5a). Nanoparticles application causes that space between monolayers is bigger as a result of agglomerates formation, in the process the film of liquid becomes thicker and foam has a greater water capacity (Fig. 5b). About nanoparticles-surfactant agglomerates formation provides flocculent precipitate visible after liquid evaporation (Fig. 5c), in addition, brine and brine with Sicol $\mathrm{Z}$ were individually evaporated and any similar effect wasn't observed.

One of the most important parameters, deciding about foams stability is salinity of water. Mineralization degree of underground Poland waters changes in a wide range (Table 2).

The effect of water salinity on unloading liquid amount during the foamability dynamic test presents Figure 6. Examination was conducted at the constant flow of gas for initial brine $100 \mathrm{~g}$. Effectiveness of foaming $1 \mathrm{wt} \%$ of Sicol $\mathrm{Z}$ and $1 \mathrm{wt} \%$ of its dispersion (containing $4 \mathrm{wt} \%$ of nanosilica) was compared.
Table 2. Mineralization of formation waters in main gas- and oil bearing formations of Poland ${ }^{15}$

\begin{tabular}{|l|c|}
\hline Gas- and oil-bearing formation of Poland & $\begin{array}{c}\text { Total } \\
\text { mineralization }[\mathrm{g} / \mathrm{l}]\end{array}$ \\
\hline $\begin{array}{l}\text { Autochthonous Miocene sandstones of } \\
\text { the Carpathian Foredeep }\end{array}$ & $4-141$ \\
\hline Main dolomite Ca2 Zechstein $\left(\mathrm{P}_{3}\right)$ & $189-380$ \\
\hline Lower Permian Rotliegend & $126-341$ \\
\hline
\end{tabular}

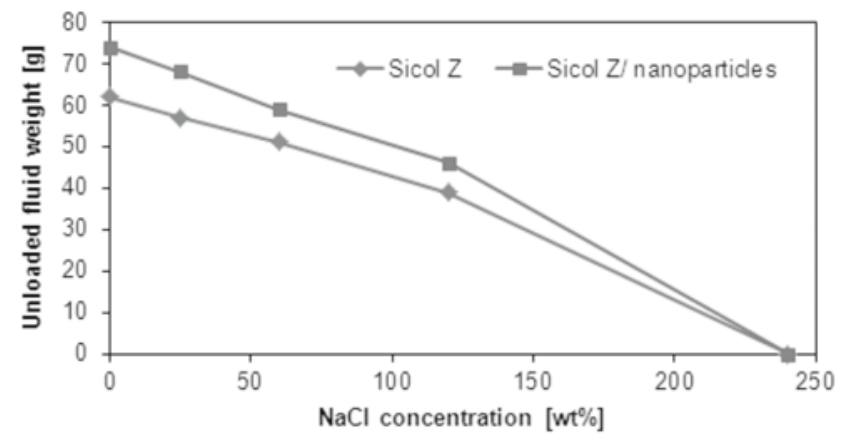

Figure 6. Effect of water salinity on the unloading liquid effectiveness

The effectiveness of foaming is the greatest in both cases for distilled water. At high water hardness additive is completely ineffective. The cause of the phenomenon is ion exchange between electrolyte and foaming agent, in addition the last one forms a salt about worse surface properties. $^{5}$. Additionally, $\mathrm{pH}$ change of the solution causes that agent becomes less active and less soluble in water. Sodium chloride causes that the double electric layer of ionic surfactants is more compressed, what reduces the thickness of the surface film. Space between adjacent bubbles tightens; in the process a smaller volume of water is unloaded. At medium water hardness the Sicol $\mathrm{Z}$ unloads about $41 \mathrm{~g}$ of foam.

Nanoparticles presence has a positive effect on brine foamability, because the presence of solid particles prevents the contact of thin surfactant layers and allows to keep more water in the foam. Formed foam should be stable, i.e. drain only in surface installation parts. Foam instability is caused by draining, coalescence and diffusion phenomena ${ }^{6,14}$. As the foam stability indicator the height of foam was assumed to be a minute and 3 hours after being shaking out. The results of foamability examination in static conditions are presented in Figure 7. Along with the increase of surfactant concentration the foam height increases, as well as its density. The more surfactant particles appear in the solution the more water can be trapped between adsorbed thin layers. Formed foams are not very stable, after 3 hours for high and low Sicol $\mathrm{Z}$ concentration there is more than twofold decline of foam height. The remaining foam has a residual character and a)

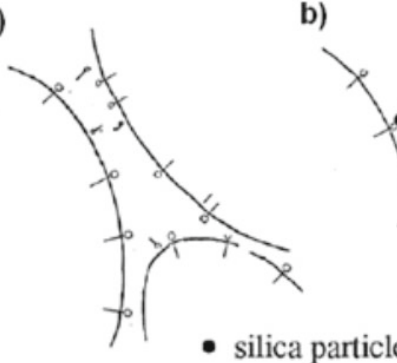

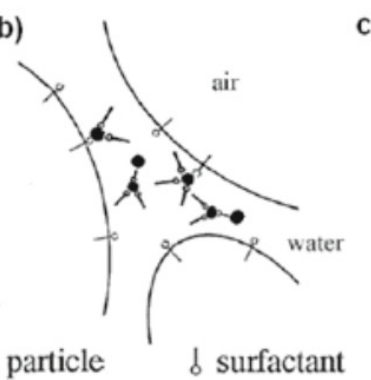

c)

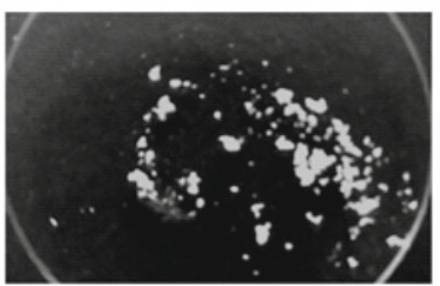

Figure 5. a) Organization of surfactant particle on the interfacial surface; b) Formation of nanoparticles-surfactant aggregates [10, modified]; c) Sediment after foam drained 


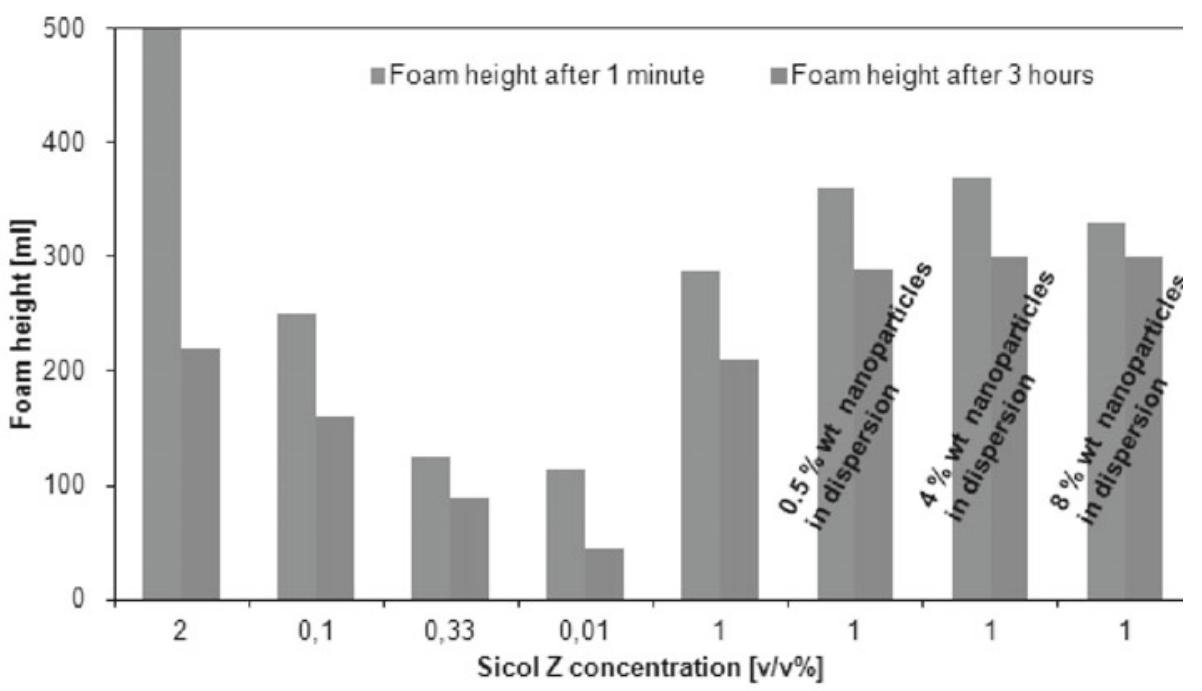

Figure 7. Liquid drainage behavior of Sicol $\mathrm{Z}$ as a function of surfactant concentration in the presence and absence of nanoparticles

contains slight amounts of water, about 1-2 grams per $100 \mathrm{~g}$ of applied brine. Along with the increase of surfactant concentration in the solution, the foam is formed more easily and quicker. Its structure changes: for low additive concentrations the formed foam is heavy, wet. Its built of a lot of small, closely compressed bubbles. For high surfactant concentrations big bubbles are formed, and the foam is light and relatively durable.

Foams containing nanoparticles behave much stabile; the residual foam height is only $15-20 \%$ smaller than initial. The arising spatial structure is stabilized by aggregates; in the process nanoparticles perform a role of small bridges connecting neighboring thin adsorbate layers. Particles presence increases the viscosity of aqueous phase, what hampers foam drain. Nanoparticles concentration doesn't impact in any significant way on the foam height, at high concentrations the height slightly decreases, because increase a specific gravity of foam.

\section{CONCLUSION}

Forming of long-lasting foams has a great importance for petroleum-refining industry (removing formation water, EOR methods and flotation), hence intense progress in their examination. The conducted examinations showed that use of nanoparticles allows to increase the efficiency of gas well deliquification even up to $20 \%$. Surfactant particle and nanosilica present synergistic action, use of $4 \mathrm{wt} \%$ of nanoparticles in dispersion allows to reduce surfactant consumption up to half. Thanks to formation of nanoparticle-surfactant aggregates the foams are more stable, have a higher density (greater water capacity) and are more resistant to salinity. Due to the complex mechanism of interaction and great practical importance further research in this area should be conducted.

\section{LITERATURE CITED}

1. Armenta, M. (2003). Mechanism and control of water inflow to wells in gas reservoirs with bottom-water drive. Doctoral dissertation, Louisiana State University, USA.

2. Oyewole, P. \& Lea, J. (2008). Artificial lift selection strategy for the life of gas well with some liquid production. Annual Technical Conference and Exhibition, 21-24 September 2008. Denver, Colorado, USA: Society of Petroleum Engineers.
3. Huang, F. \& Nguyen, D. (2012). Optimized foamers for natural gas well deliquification: A statistical design approach. Fuel 97 (7), 523-530. DOI: 10.1016/j.fuel.2012.02.062.

4. Solesa, M. \& Sevic, S. (2006). Production Optimization Challenges of gas wells with liquid loading problem using foaming agents. SPE Russian Oil and Gas Technical Conference and Exhibition, 3-6 October 2006. Moscow, Russia: Society of Petroleum Engineers.

5. Yang, J., Jovancicevic, V. \& Ramachandran, S. (2007). Foam for gas well deliquification. Colloids and Surfaces A: Physicochem. Eng. Aspects 309, 177-181. DOI: 10.1016/j. colsurfa.2006.10.011.

6. Karakashev, S. \& Grozdanova, M. (2012). Foams and antifoams. Adv. Coll. Interf. Sci. 176 -177, 1-17. DOI: 10.1016/j. cis.2012.04.001.

7. Paria, S. \& Khilar, K. (2004). A review on experimental studies of surfactant adsorption at the hydrophilic solid-water interface. Adv. Coll. Interf. Sci. 110, 75-95. DOI: 10.1016/j. cis.2004.03.001.

8. Tiberg, F., Brinck, J. \& Grant, L. (2000). Adsorption and surface-induced self-assembly of surfactants at the solid-aqueous interface. Current Opinion in Colloid \& Interface Science 4, 411-419. DOI: 10.1016/S1359-0294(00)00016-9.

9. Horozov, T. (2008). Foams and foam films stabilised by solid particles. Current Opinion in Colloid \& Interface Science 13, 134-140. DOI: 10.1016/j.cocis.2007.11.009.

10. Dong, X., Xu, J., Cao, C., Sun, D. \& Jiang, X. (2010). Aqueous foam stabilized by hydrophobically modified silica particles and liquid paraffin droplets. Colloids and Surfaces A: Physicochem. Eng. Aspects 353, 181-188. DOI: 10.1016/j. colsurfa.2009.11.010.

11. Hunter, T., Wanless, E., Jameson, G. \&. Pugh, R. (2009). Non-ionic surfactant interactions with hydrophobic nanoparticles: Impact on foam stability. Colloids and Surfaces A: Physicochem. Eng. Aspects 347, 81-89. DOI: 10.1016/j. colsurfa.2008.12.027.

12. Liu, Q., Zhang, S., Sun, D. \& Xu, J. (2010). Foams stabilized by Laponite nanoparticles and alkylammonium bromides with different alkyl chain lengths. Colloids and Surfaces A: Physicochem. Eng. Aspects 355, 151-157. DOI: 10.1016/j. colsurfa.2009.12.003.

13. Binks, P. \& Horozov, S. (2006). Colloidal particles at liquid interfaces. Cambridge, UK: Cambridge University Press.

14. Schramm, L.L. (2000). Surfactants, Fundamentals and Application in the Petroleum Industry. Cambridge, UK: Cambridge University Press.

15. Zubrzycki, A. (2011). Fundamentals of petroleum geology. Krakow, Poland: Wydawnictwa AGH. (in Polish) 